九州大学学術情報リポジトリ

Kyushu University Institutional Repository

\title{
Boundary Conditions for Grain and Soybean Dust Explosion
}

Chuma, Yutaka

Laboratory of Agricultural Process Engineering, Faculty of Agriculture, Kyushu University

Shemsanga, Kassim H. H.

Laboratory of Agricultural Process Engineering, Faculty of Agriculture, Kyushu University

Uchida, Susumu

Laboratory of Agricultural Process Engineering, Faculty of Agriculture, Kyushu University

https://doi.org/10.5109/23766

出版情報：九州大学大学院農学研究院紀要. 27 (3/4)，pp.127-141，1983-02. Kyushu University バージョン：

権利関係 : 


\title{
Boundary Conditions for Grain and Soybean Dust Explosion
}

\author{
Yutaka Chuma, Kassim H. H. Shemsanga \\ and Susumu Uchida \\ Laboratory of Agricultural Process Engineering, Faculty of \\ Agriculture, Kyushu University 46-05, Fukuoka 812
}

(Received August 24, 1982)

\begin{abstract}
Grain and soybean dust explosion was investigated in order to determine the conditions that can cause an explosion to take place in a closed space such as in side a grain elevator, conveyor, miller and silo. The main parameters, which were investigated, were minimum ignition temperature, minimum explosible dust concentration, explosion pressure, dust particle size and moisture content. In all the materials and at all moisture contents, a concentration of about $1,000 \mathrm{~g} / \mathrm{m}^{3}$ was observed to give the maximum explosion pressure and maximum rate of pressure rise. The delayed time at this concentration was minimum. At any given dust particle size the ignition temperature was highest in rice husks followed by wheat, corn, milled rice and soybean in ascending order. However, in terms of maximum pressure and maximum rate of pressure rise, the order was from wheat, rice husks, soybean, corn to milled rice in descending order. It was observed that dust particle size played a major role on the explosibility of any dust material. Moisture content affected the ignition temperature and the maximum rate of pressure rise, but did not affect the maximum explosion pressure and delayed time of explosion.
\end{abstract}

\section{INTRODUCTION}

The mechanization of handling, processing and storage of grains, while it has increased the efficiency of the operations, it has been accountable for large losses in human lives and materials. These losses have been mainly due to dust explosions which has been taking place as early as the onset of the merchandize of these materials. Dust explosion has been reported as early as 1785 in Turin, Italy, by Maness (1979). However, the contribution of the grain dust to these explosions were not realized until late 1800 s or early 1900 s through tests on the explosibility of coal dusts. Ever since research on this field has been extensively performed, however, unfortunately up to now explosions are still hounding the grain industry and human life is always in danger.

Webster (1979) stated, "No matter how well an installation is designed it is not possible with the current technology, to guarantee that there will not be an explosion in the facility". The elimination of this problem has failed due to insufficient research and partly due to the complexity of the explosions and inconsistency of the available data. The conditions determining the ex- 
plosibility of the grain dust has been reported by Schmitt (1979) to be dust concentration, dust size and distribution, ignition source, oxygen concentration and a closed place. These factors especially dust concentration has been reported to be varying from researcher to researcher. Furthermore, these factors depend on the material from which the dust was obtained as well as the variety of the material. Due to these factors, the research was carried to determine the conditions for corn, wheat, milled rice, rice husks and soybean dust explosions so as to obtain accurate data that could be applied with the other collected data, Chuma et al. (1981) for the design of a storage facility for the stock-piling of these products.

With the present handling, processing and storage methods, it has been inevitable that the dust occurs in the grains from the harvesters to the storage facilities. In some cases the dust existence in the facilities cannot be prevented due to impact of the grains and the mechanical moving parts of harvesters and conveyor belts and buckets and during loading and unloading in wagons or/and storage facilities. In processing, the dust could be the desired end product for example in flourmills. The regrettable source of dust is that dust which is added deliberately into the grain in order to add up weight and export this dust in disguise of grain.

\section{LITERATURE REVIEW}

As stated earlier that grain dust is found in almost all the handling, processing and storage facilities, the concentration of the dust will vary from location to location in the facilities. Wade et al. (1979) carried out dust sampling investigations in an elevator and found out that the concentration in the working area was $30-50 \mathrm{~g} / \mathrm{m}^{3}$ compared to $10-1,200 \mathrm{~g} / \mathrm{m}^{3}, 4 \mathrm{~g} / \mathrm{m}^{3}$ and $20-85$ $\mathrm{g} / \mathrm{m}^{3}$ in the head and boot, loading point and inside discharge chutes, respectively. These concentrations were reported to fall in the explosible range. The size of these dusts was reported to be having mean diameters of 15,20 and 16-120 milli-microns for the working area, settled dust and equipments, respectively. So long as these dusts are settled and left undisturbed, they will not course explosions. However, Schmitt (1979) reported that a primary explosion which may not be devastating occurring at some point may cause structure vibrations and hence kicking up of the stationary accumulated dust to form a dust cloud which can be in the explosible range.

The size and composition of the dust varies depending on the material and the handling conditions of the grain. The properties of the grain dust has been investigated in elevators and silos by Martin et al. (1979). The researcher reported the dust to be composed of coarse and fine dust where the coarse dust was composed of irregularly shaped grain and trashy fragments. The fine dust from wheat, soybeans and sorghum was reported to consist of trichome spheroids which are usually found on the plants, soybean pods, brush end of wheat kernels and grain sorghum hulls. The size of these dusts was 0.05-0. $20 \mathrm{~mm}$ in length and 0.01-0. 03mm in diameter. Apart from the trichomes, the dusts included starch granules which were $0.005-0.030 \mathrm{~mm}$ 
in diameter. Yoshizaki and Takigawa (1979) reported the dust in storage, processing and drying facilities to be mainly composed of pubescent hairs detached from the grain. Insect infestation has been reported by Boles and Martin (1979) to contribute to dust in grains. The researchers reported $125 \mathrm{~g}$ and $7 \mathrm{~g}$ of dust arising from grain borers and rice weevils when 1,250 insects infested $125 \mathrm{~g}$ of grain. This dust was found to be in the explosible range. The composition of the dust was found to be of starch granules and grain fragments of less than 43 milli-microns. The fecal pellets from the insects was also reported to be explosible.

For a dust of sufficient concentration suspended in a closed space to explode an ignition source is necessary. In grain elevators and conveyors the friction between the moving parts such as bearing and shafts can give rise to high temperatures enough to act as an ignition source. Friction heating as a source of ignition has been reported by Finn (1978) in a grain elevator. Another source of ignition has been reported by Butterworth (1979) to be static electrical charges. The author suggested that charges can accumulate on elevator load, suspended dust cloud, components made from insulating material and on electrically isolated items of the plants. The author further suggested that electrical charges can be generated by the passage of insulated conveyor belts over metal rollers or pulleys and the charge can then give rise to sparks at the rollers or other neighboring materials. According to the author, it is interesting to note that the workers in these facilities can be a source of ignition not only through carelessness such as smoking and welding, but through sufficient energetic spark emission from their bodies and clothes. Ignition sources in 100 explosions have been summarised by Wishna (1979). Twenty-nine of of the explosion were due to frictional sparks, while $24 \%, 15 \%, 5 \%, 3 \%, 2 \%$ and $24 \%$ were caused by sparks and tramp metal, local over heating, static sparks, electrical equipments, cutting and welding and others, respectively. The ignition source should have enough energy to initiate an explosion. Butterworth (1979), reported that under optimum conditions a spark energy of 0.2 milli-joules is sufficient to ignite common hydrocarbon vapor-air mixtures, while for corn starch he reported an energy of 0.3 milli-joules. For ignition caused by over heating, the minimum ignition temperature of the material is of importance. Wishna (1979) reported the ignition temperature for wheat, corn and rice to be $500^{\circ} \mathrm{C}, 400^{\circ} \mathrm{C}$ and $470^{\circ} \mathrm{C}$, respectively, while the minimum ignition temperature for their mixture was reported to be $430^{\circ} \mathrm{C}$.

The hazard caused by the explosion will depend on the pressure rise during an explosion. The pressure rise rate and the maximum pressure was reported to depend on the content of volatile components and level of oxygen in the dust by Naito (1979). As the volatile matter and oxygen increases, the pressure as well as the rate of pressure rise increases also. Yoshizaki and Takigawa (1979), investigated the effect of moisture content and concentration of the maximum explosion pressure as well as the maximum rate of pressure rise on rice dust while Brasie (1979) investigated the effect of corn starch on the maximum explosion pressure. The maximum explosion pressure was reported by the authors to increase with increase in the concentration of the 
dust reaching an optimum value at about $1,000 \mathrm{~g} / \mathrm{m}$ ". The maximum rate of pressure rise was found to decrease with increase in the moisture content. The moisture content was observed not to affect the maximum explosion pressure significantly.

\section{EXPERIMENTAL MATERIALS AND METHOD}

The explosibility of soybean, corn, wheat, milled rice and rice husks were investigated. The properties and history of the materials are as that which has been reported before, Chuma et al. (1981). "Dusts" from these materials were obtained by milling the whole grains in a small laboratory portable miller, (SK-M2) manufactured by Kyoritsu Kogyo Company. Milled rice and rice husks were obtained by dehusking rough rice using Satake Grain Testing Mills, NO 18009. The materials were milled for one minute, 50 grams at a time and the milling was continued until about two killograms of the "dust" was obtained for each material. The "dust" was then sieved in order to get different "dust" particle sizes. Taylor sieves were used in the sieving. The sieves were vibrated on a vibrator manufactured by Kyushu Maruto Company for 30 minutes. During sieving, taping of the sieves by an wooden stick was found to be necessary in order to reduce sieve blinding as well as contamination of the larger particles by the smaller particles.

In order to test the "dusts" at different moisture contents, the "dusts" were placed in dessicators containing different concentrations of lithium chloride solutions. The samples were left for one day which was assumed to be sufficient for the "dust" to attain equilibrium moisture content. After the samples were moisture reconditioned, they were then sealed in air tight bottles and transported by car to the Coal Mining Research Center, Kyushu, Nogata City, which is about 40 kilometers from Kyushu University for the explosion tests. The tests were always started early in the morning to make sure that each experimental material was tested on the same day. The tests were continued for three months, from November, 1981 to February, 1982.

\section{Ignition temperature apparatus}

Fig. 1 shows the ignition temperature apparatus. The apparatus mainly consists of a furnace which can be heated up to $1,000^{\circ} \mathrm{C}$. The sample is forced into the furnace by air from a compressor after being regulated through a mercury manometer. The sample on flowing through the furnace is heated up to the temperature of the furnace. Depending on the ignition temperature of the material, the sample will be ignited and explode when passing through the furnace and a flame will be observed at the bottom of the furnace. For each experimental run, the furnace was first heated to $1,000^{\circ} \mathrm{C}$ after which half table spoon full of the sample was put into the sample holder. The air from the compressor was regulated and then released into the sample holder through a magnetic valve. When a flame was observed at the bottom of the furnace, the temperature of the furnace was decreased by $10^{\circ} \mathrm{C}$. This process was repeated for each material and dust particle size until no more flame 
could be observed at the bottom of the furnace. The temperature below which no more flame could be observed was recorded as the minimum ignition temperature.

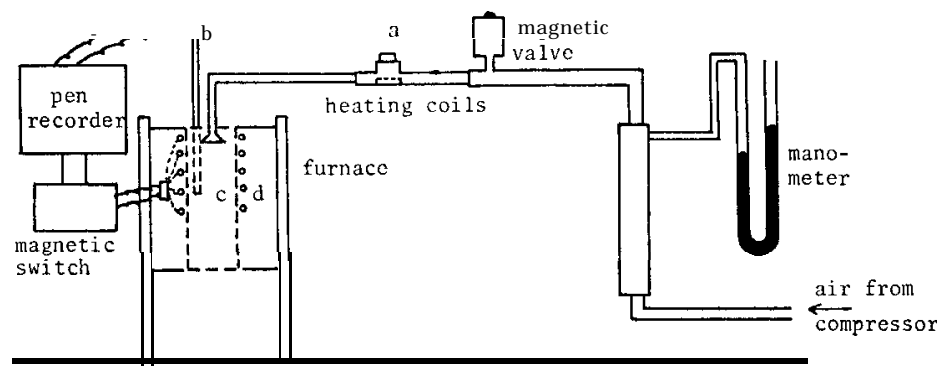

Fig, 1. Schematic diagram of ignition apparatus. a, sample holder; $b$, thermocouple ; $c$, ignition chamber ; d, insulator.

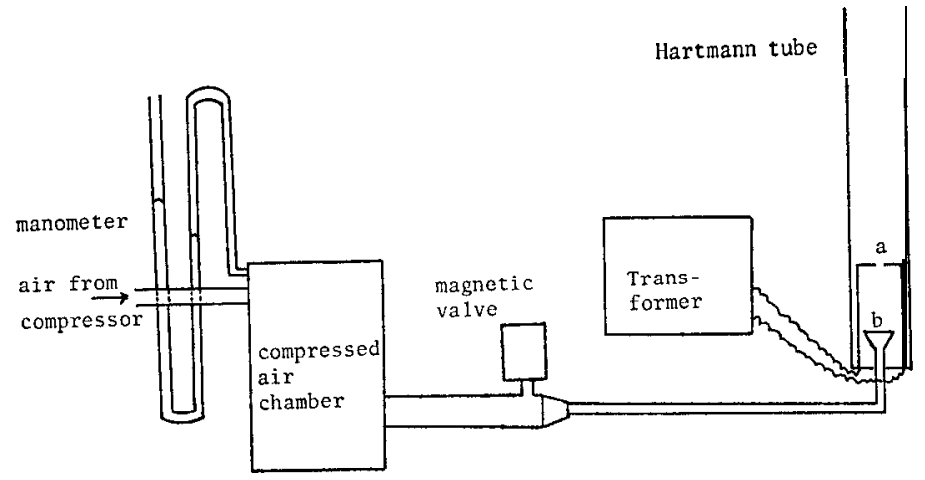

Fig. 2. Schematic diagram of a modified Hartmann apparatus. a, spark gap; b, sample holder.

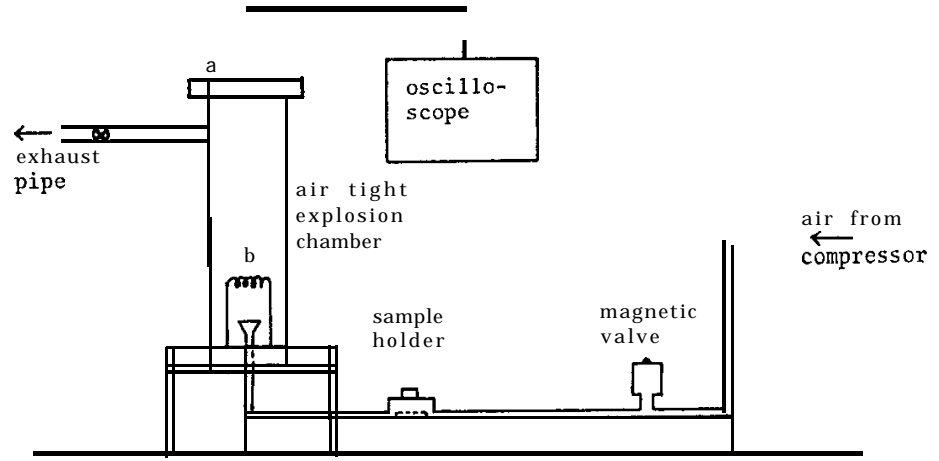

Fig. 3. Schematic diagram of explosion pressure apparatus. a, pressure transducer; b, spark gap; c, sample holder. 


\section{Explosion concentration apparatus}

The experimental apparatus is shown on Fig. 2. The apparatus is a modification of the Hartmann apparatus. Essentially, the apparatus forces the sample in the same way as in the ignition temperature apparatus through a spark gap of about $4 \mathrm{~mm}$ and the material is exploded by a spark from tungsten electrodes. The explosion of the material will depend on the concentration and particle size of the dust. For each dust size, the concentration of the dust was varied from high to low levels until the dust could not be exploded. The concetration below which the dust could not be exploded was recorded as the minimum explosible dust concentration.

\section{Explosion pressure apparatus}

The apparatus as shown in Fig. 3 mainly consists of a 3,500 cc air tight chamber. As in the concentration explosion apparatus, the sample is forced through a spark gap inside the chamber. The pressure in the chamber during an explosion is monitored by a pressure transducer at the top of the chamber and then recorded on a magnetic oscillograph.

\section{RESULTS AND DISCUSSION}

The minimun ignition temperature for wheat and soybeans is shown in

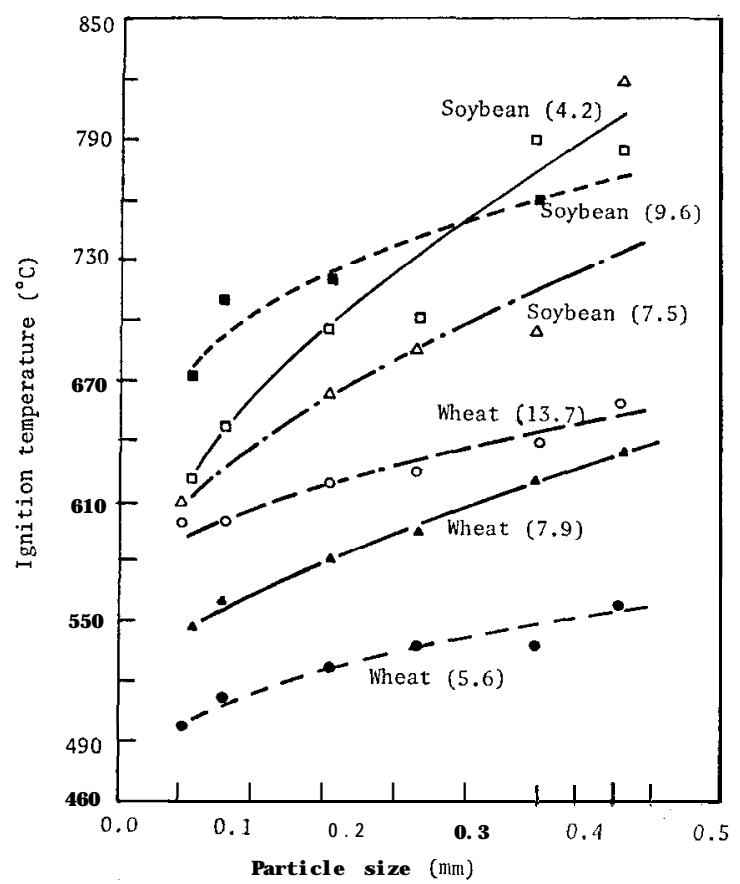

Fig. 4. Minimum explosion temperature for wheat and soybean dusts as affected by dust particle size and moisture contents ( $\%$ d.b.). 


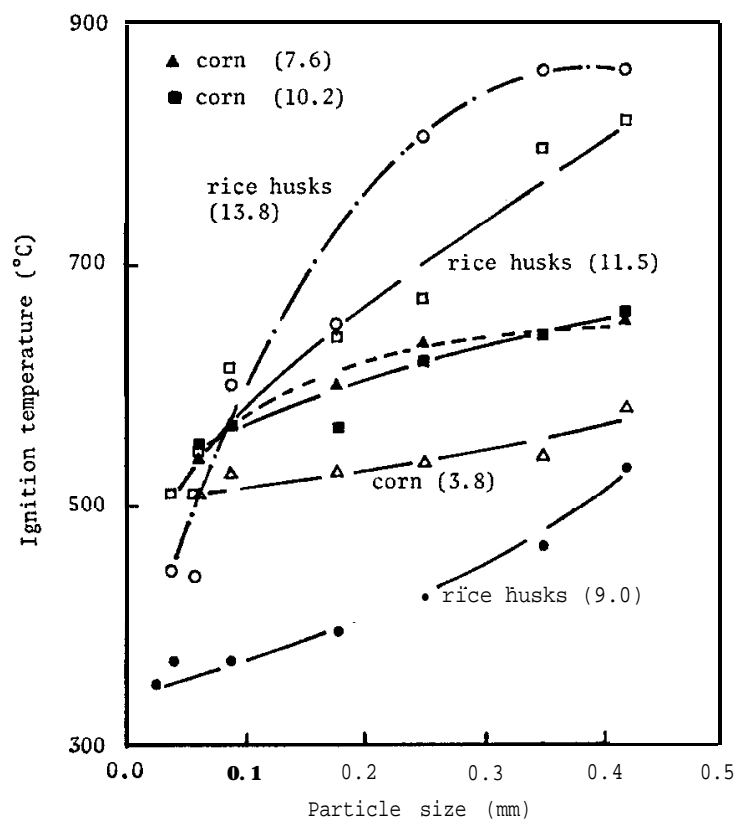

Fig. 5. Minimum ignition temperature for rice husks and corn dusts as affected by dust particle size and moisture content (\% d.b.).

Fig. 4 and that for rice husks and corn is shown in Fig. 5. It was observed that as the moisture content of the dust increases, the ignition temperature also increases. The effect of the moisture content was however, more remarkable on wheat and least in soybeans. The increase in the ignition temperature with moisture content for rice husks and corn was more rapid when the moisture content increased from $9 \%$ to $11.5 \%$ and from $3.8 \%$ to $7.6 \%$, respectively, than thereafter. This phenomenon was also observed on wheat but at larger dust particles. For all the tested materials, the ignition temperature increased exponentially with increase in dust particle size. Soybean was observed to have the highest ignition temperature followed by corn, wheat and rice husks in descending order. The high ignition temperature for soybeans compared to the other materials was also reported by Breipohl et al. (1979).

The minimun explosible dust concentration is shown in Fig. 6 for wheat and rice husks. As in the minimum ignition temperature curves, the concentration increased almost in the same magnitude as the moisture content of the dust increased. The concentration increased exponentially as the dust particle size increased. However, there was a maximum dust particle size that could be exploded at any given moisture content. This maximum dust particle size was observed to be $0.087 \mathrm{~mm}$ and $0.061 \mathrm{~mm}$ for rice husks at $9.0 \%, 11.5 \%$ and $13.8 \%$ moisture contents, respectively. For wheat, particles as large as $0.42 \mathrm{~mm}$ could be exploded. Such a greater difference could be due to the 


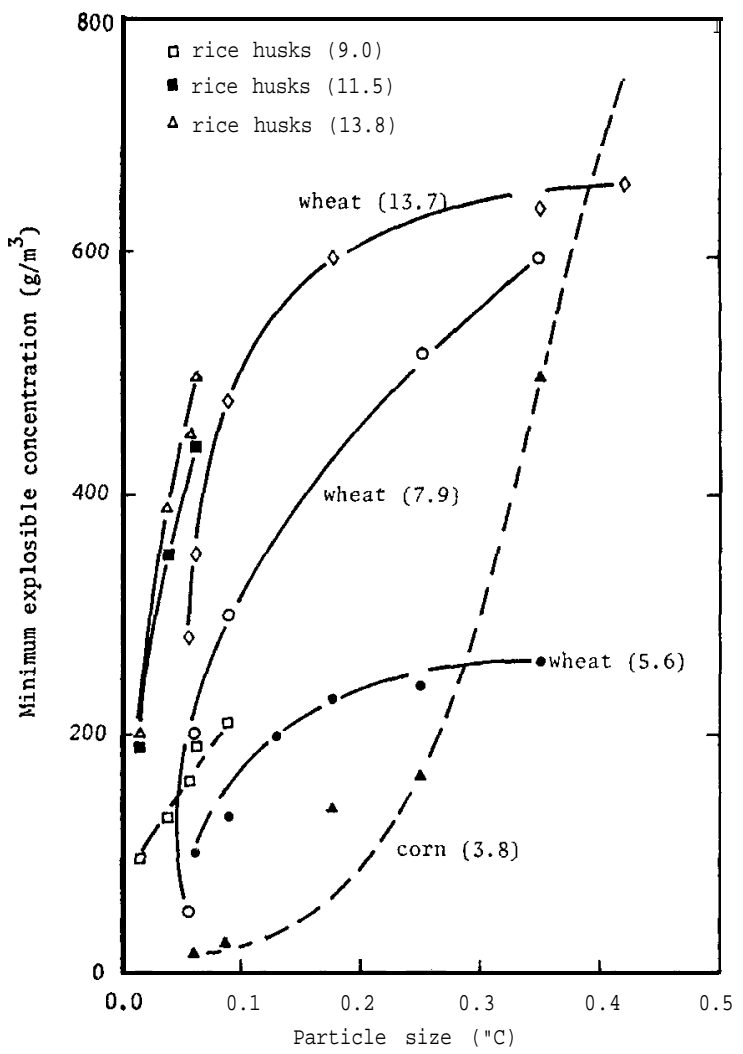

Fig. 6. Relationship between dust particle size and minimum explosible dust concentration at different moisture contents ( $\$ 6$ d.b.).

shape of the particles which determines the surface area and floating properties. The rice husk dusts were observed to be rod like compared to the almost roundish wheat dusts which could naturally have greater surface area and good floatability.

Fig. 7 shows a typical pressure-time curve. For each explosion curve, the delayed time $\left(P_{0}-P_{1}\right)$, maximum pressure, $P_{\mathrm{m}}$ and maximum rate of pressure rise $(\mathrm{d} P / \mathrm{d} t)$ in the chamber were determined, The delayed time for rice husks at $11.5 \%$ moisture content at different particle sizes is shown in Fig. 8. The other materials are shown in Table 1 . The delayed time was found to increase with increase in the dust particle size. As the dust concentration increase, the delayed time decreased reaching a minimum value at $1,000 \mathrm{~g} / \mathrm{m}^{3}$ and then increased as the concentration increased. This phenomenon was observed in all the materials and at all moisture contents. The effect of the dust concentration was however, more pronounced in the larger dust particles than in the smaller particles.

When an explosion takes place, the extensiveness of the damage will 
Table 1. Delayed explosion time (sec) for selected grain dusts at 1,000 $\mathrm{g} / \mathrm{m}^{3}$ dust concentration 1

\begin{tabular}{|c|c|c|c|c|c|c|c|c|}
\hline \multirow{2}{*}{ Material } & \multirow{2}{*}{$\begin{array}{c}\text { M. C. } \\
(\% \text { d.b. })\end{array}$} & \multicolumn{7}{|c|}{ Dust particle size $(\mathrm{mm})$} \\
\hline & & 0.25 & 0.177 & 0.087 & 0.061 & 0.053 & 0.038 & 0.025 \\
\hline Rice husks & $\begin{array}{r}9.0 \\
13.8\end{array}$ & - & $\begin{array}{r}0.50 \\
-\end{array}$ & $\begin{array}{l}0.45 \\
0.30\end{array}$ & 0.26 & $\begin{array}{l}0.16 \\
0.13\end{array}$ & $\begin{array}{l}0.09 \\
0.08\end{array}$ & $\begin{array}{l}0.06 \\
0.08\end{array}$ \\
\hline Wheat & $\begin{array}{r}5.6 \\
7.9 \\
13.7\end{array}$ & $\begin{array}{l}0.16 \\
0.18 \\
0.22\end{array}$ & $\begin{array}{l}0.14 \\
0.16 \\
0.22\end{array}$ & $\begin{array}{l}0.08 \\
0.24 \\
0.21\end{array}$ & $\begin{array}{l}0.24 \\
0.22 \\
0.19\end{array}$ & $\begin{array}{l}0.10 \\
0.16 \\
0.20\end{array}$ & 二 & $=$ \\
\hline Soybean & $\begin{array}{l}4.2 \\
7.5 \\
9.6\end{array}$ & - & $\begin{array}{l}0.60 \\
0.44 \\
-\end{array}$ & $\begin{array}{l}0.39 \\
0.26 \\
0.48\end{array}$ & $\begin{array}{l}0.32 \\
0: 28\end{array}$ & 0.18 & E & - \\
\hline Corn & $\begin{array}{l}3.8 \\
7.6\end{array}$ & 0.52 & $\begin{array}{l}0.46 \\
0.52\end{array}$ & 8.30 & $0 . \overline{15}$ & - & - & - \\
\hline Milled rice & 10.0 & 0.32 & 0.34 & 0.32 & - & - & - & - \\
\hline
\end{tabular}

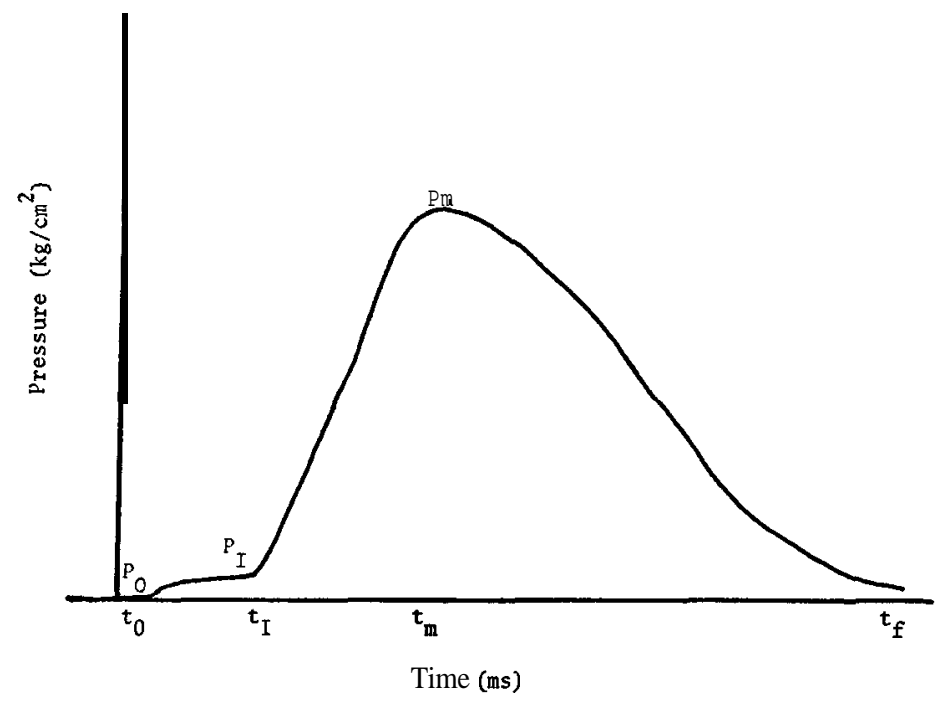

Fig. 7. Typical explosion pressure-time curve.

depend on the maximum explosion pressure and the strength of the structure to withstand the pressure. Fig. 9 shows the maximum explosion pressure for rice husks at $9.0 \%$ moisture content and at different dust concentrations and dust particle sizes. The pressure was observed to increase with a decrease in the dust particle size. At dust particle sizes greater than $0.038 \mathrm{~mm}$, the pressure increased with increase in concentration reaching a peak at 1,000 $\mathrm{g} / \mathrm{m}^{3}$, except for the $0.053 \mathrm{~mm}$ particle size where the peak was observed at 800 $\mathrm{g} / \mathrm{m}^{3}$. The $0.025 \mathrm{~mm}$ particle size did not reach a peak which was assumed to be above the tested concentration range. For the other materials, the peak was observed to lie between $800 \mathrm{~g} / \mathrm{m}^{3}$ and $1,000 \mathrm{~g} / \mathrm{m}^{3}$ at all particle sizes. The 


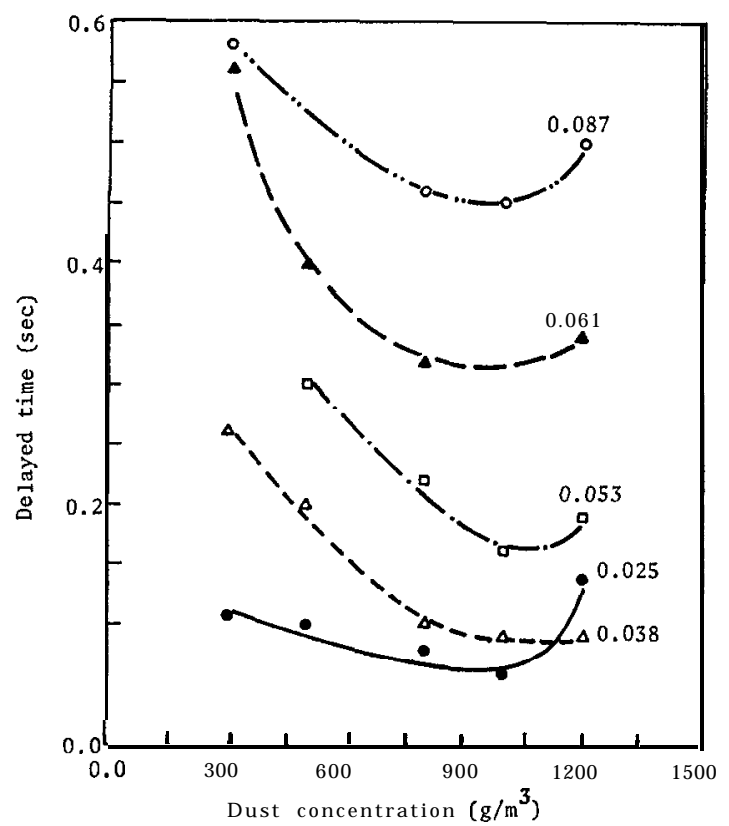

Fig. 8. Effect of dust concentration on explosion delayed time for rice husks at different dust particle sizes $(\mathrm{mm})$.

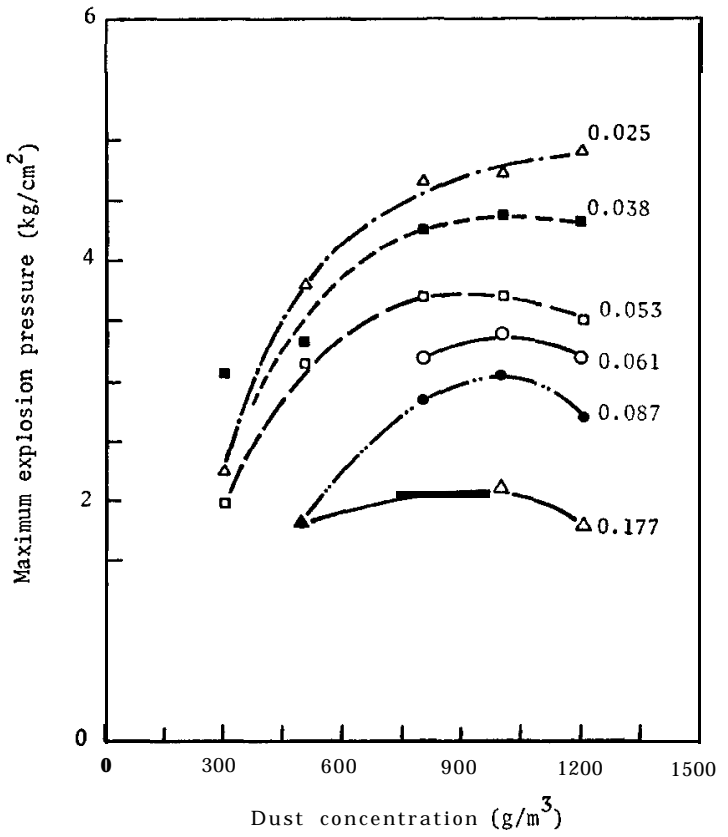

Fig. 9. Effect of dust concentration on maximum explosion pressure for rice husks $(9.0 \%$ d.b.) at different dust particle sizes $(\mathrm{mm})$. 
concentration at which the peak was observed was lower than that reported by Yoshizaki and Takigawa (1979).

Fig. 10 shows the effect of moisture content on the maximum explosion pressure. From 300 to $1,200 \mathrm{~g} / \mathrm{m}^{3}$ concentrations, the pressure was observed to decrease with increase in-moisture content, while at the other moisture contents, the pressure increased with increase in the moisture content. However, these variation in the pressure with moisture content were small enough to be neglected, except at $300 \mathrm{~g} / \mathrm{m}^{3}$ concentration.

Fig. 11 compares the maximum explosion pressure of all the tested materials at the same dust particle sizes. The pressure for rice husks and wheat above $300 \mathrm{~g} / \mathrm{m}^{3}$ concentration was not significantly different. These materials gave higher pressures than the other materials. The lowest pressure was observed in milled rice followed by corn and soybean in descending order. The low maximum explosion pressure for milled rice and corn would indicate that even if an explosion takes place, less damage will be done to the facility as well as the surrounding structures.

Although the maximum explosion pressure determines the damage to the structure, the rate of the pressure rise when an explosion takes place is equally important. A high maximum rate of pressure rise would send shock waves to the structure wall which may not be evenly distributed along the wall depending on the position of the occurrence of the primary explosion.

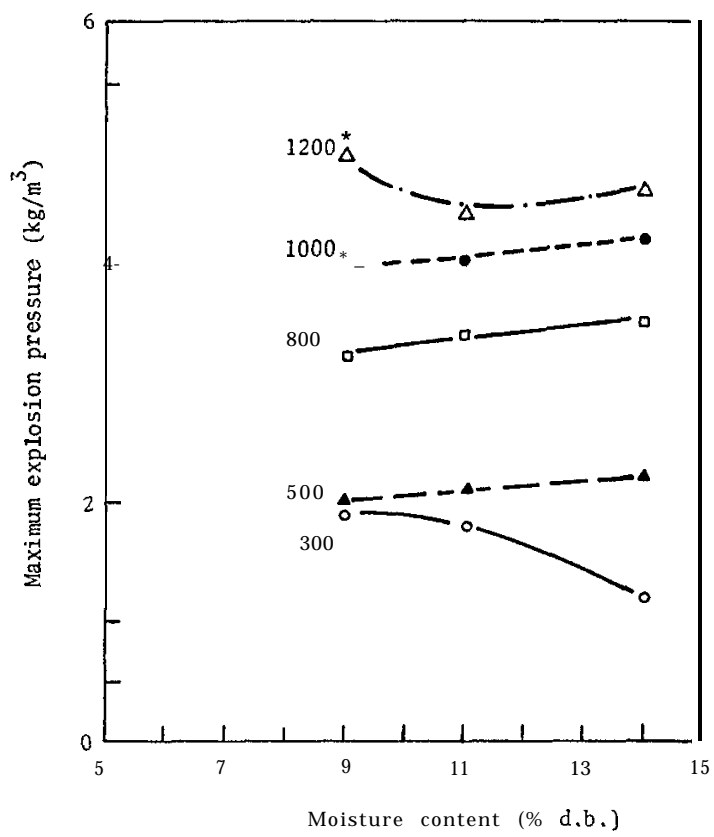

Fig. 10. Effect of moisture content on maximum explosion pressure for rice husks at different dust concentrations and $0.038 \mathrm{~mm}$ particle size. *: Concentration in $\mathrm{g} / \mathrm{m}^{3}$. 


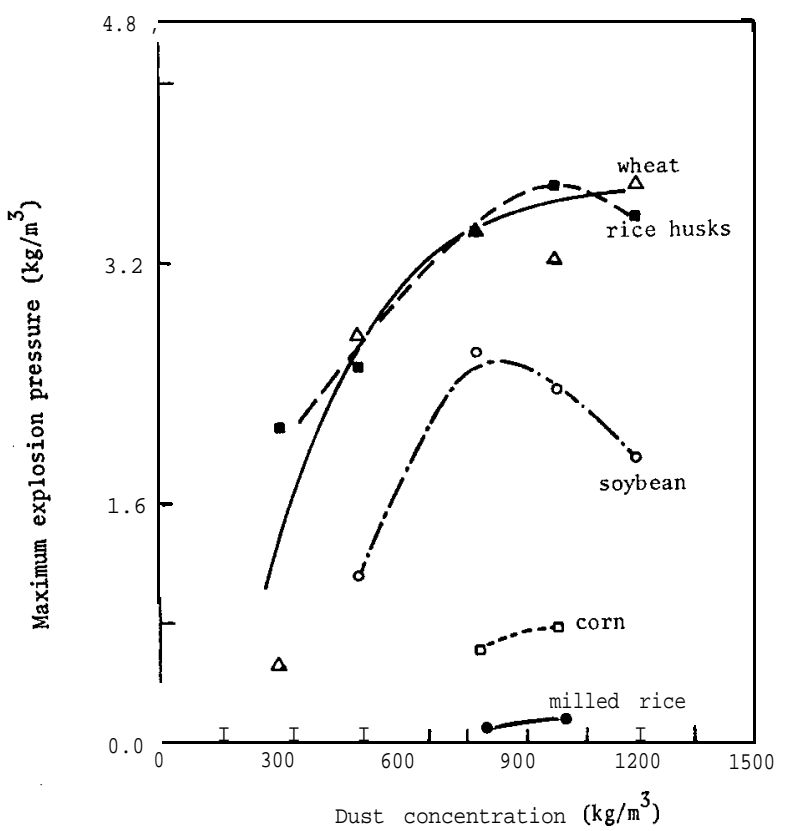

Fig. 11. Relationship between dust concentration and maximum explosion pressure for selected grains at about $10 \%$ (d.b.) moisture content and $0.061 \mathrm{~mm}$ dust particle size.

Such a dynamic shock wave will give rise to large localized and instantaneous stress on the wall which can crack or even crumble the whole structure. The maximum rate of pressure rise for rice husks at $11.5 \%$ moisture content is shown in Fig. 12. The pattern of the curves are the same as those for maximum explosion pressure. At all particle sizes the peak was observed at 1,000 $\mathrm{g} / \mathrm{m}^{3}$. At the other moisture contents as well as for wheat, the peak was observed at this level of concentration.

Fig. 13 shows the relationship between the ignition temperature and the maximum explosion pressure for wheat at three different moisture contents. A linear relationship could be observed between the two parameters. The relationship is of significant importance in that it could be used in the design of relief vents in a closed space such as a silo and also it could be used in the selection of the construction material which could resist the pressure once an explosion happens to take place. Moreover, the moisture content of the material could be kept at a level based on the strength of the structure as well as the vent space of the given facility.

\section{CONCLUSION}

The explosibility of grain dust is mainly dependent on the dust particle size. As the dust particle size increases the maximum explosion pressure and 


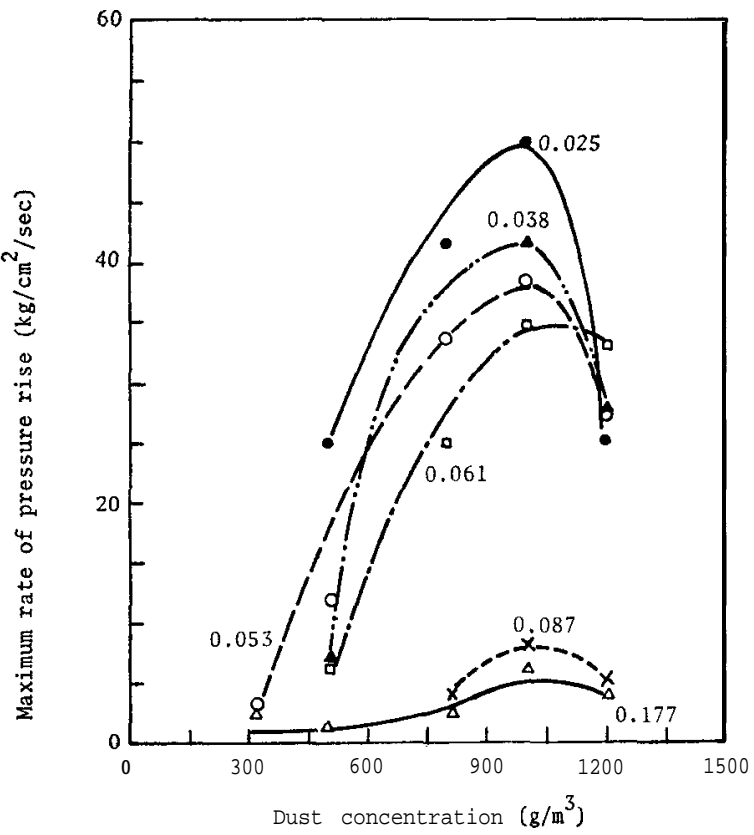

Fig. 12. Relationship between dust concentration and maximum rate of pressure rise at different dust particle sizes for rice husks at $11.5 \%$ (d.b.) moisture content.

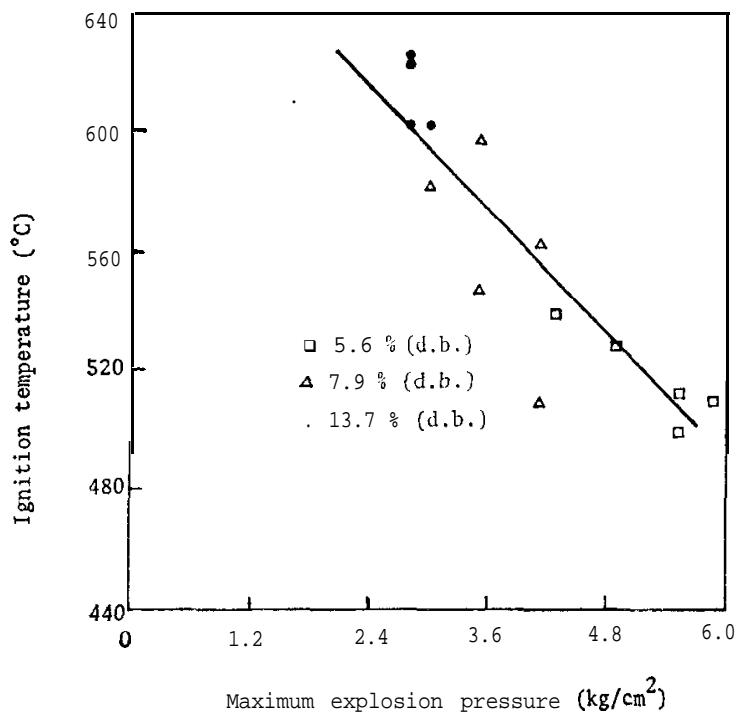

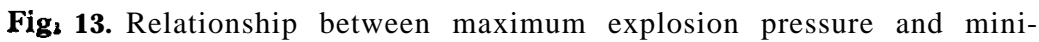
mum ignition temperature for wheat dust at $1,000 \mathrm{~g} / \mathrm{m}^{3}$ dust concentration. 
the maximum rate of pressure rise increases, while the ignition temperature and delayed time decreases. The dust concentration at $1,000 \mathrm{~g} / \mathrm{m}^{3}$ is of significant importance in that the maximum explosion pressure and the maximum rate of pressure rise reached a maximum value while the delayed time attained a minimum value. The minimum explosible dust concentration was greatly affected by the dust particle size and the nature of the material. For rice husks, dust particles greater than $0.087 \mathrm{~mm}$ could not be exploded at any given concentration, while for wheat particles as large as $0.42 \mathrm{~mm}$ could he exploded. The greatest damage that could be expected in case of an explosion would be that from wheat followed by rice husks due to the high maximum explosion pressure. The least damage would be expected in milled rice and corn dust exp!osions. Dust in wheat and rough rice processing, handling and storage facilities should therefore be minimized as much as possible so as to reduce explosion risks. Storage of milled rice instead of rough rice would reduce explosion risks.

\section{ACKNOWLEDGEMENTS}

The authors are indebted to the Coal Mining Research Center, Kyushu, Nogata City for providing us with the experimental apparatuses and equipments without which the research could not have been carried. Special thanks are extended by the authors to Dr. Y. Tashiro, Chief of the Research Center and Mr. T. Tominaga, company employee for their personal interest and valuable help to the research work. Gratitude is extended to the Ministry of Agriculture, Forestry and Fisheries for providing the funds for the study. The research was also supported by the Ministry of Education through Grant in Aid for Co-operative Research A (No. 548053).

\section{REFERENCES}

Brasie, W. C. 1979 Guidelines for estimating damage from grain dust explosions. Proc. Internat. Symp. on Grain Dust, [1979]: 321-342

Breipohl, G., T. W. Leister and J. F. Merklin 1979 Shock tube studies of the mechanism of grain dust ignition. Proc. Internat. Symp. on Grain Dust, (1979) : 191-211

Boles, H. P. and C. R. Martin 1979 The role of insects in dust production. Proc.Internat. Symp. on Grain Dust, (1979) : 293

Butterworth, G. J. 1979 Monitoring and assessment of electrostatic ignition hazards. Proc. Internat. Symp. on Grain Dust, [1979] : 380-395

Chuma, Y., S. Uchida, K. H. H. Shemsanga and T. Matsuoka 1981 Bulk physical and thermal properties of cereal grains as affected by moisture content. J.Fac. Agr., Kyushu Univ., 26: $57-70$

Finn, W. D. L. 1978 Fire and explosion in a terminal-Case history and evaluation. Internat. Symp. on Grain Elevator Explosions., 1: 384-396

Maness, J. E. 1979 Grain dust explosions. Amer. Soc.Agric. Engineers Paper, no. 79-3511: $1-16$

Martin, C. R., F. S. Lai, C. S. Chang and B. S. Miller 1979 Reducing dust cmissiom by use of a grain nozzle. Proc. Internat. Symp. on Grain Dust, (1979) : 453-362 
Naito, M. 1979 Tests for dust explosibility and some problems on practicle application of test results. Proc. Internat. Symp. on Grain Dust, [1979] : 131-149

Schmitt, H. W. 1979 Dust concentration measurements in grain elevators and related explosion hazard evaluations. Proc.Internat. Symp. on Grain Dust, [1979]: 33-46

= Wade, F. J., A. L. Hawk and C. A. Watson 1979 A survey of grain dust properties at large grain terminals. Proc.Internat. Symp. on Grain Dust, [1979] : 49-68

Webster, N. W. 1979 Equipment for reducing dust explosions. Amer. Soc.Agric, Engineers Paper. no. 79-3512: 1-12

Wishna, S. 1979 Detection of potential heat ingnition sources by thermography. Proc. Internat. Symp. on Grain Dust, [1979] : 367-379

Yoshizaki, S. and T. Takigawa 1979 Explosion characteristics of dust clouds in paddy drying and milling facilities in Japan. Proc. Internat. on Grain Dust, [1979]: 97-117 